\title{
Design and selection of servomotor for radial aircraft tire secondary molding machine
}

\author{
Chaoqun Wang
}

Qingdao Double Star Tire Co., Ltd., Qingdao 266400

\begin{abstract}
The company Meridian Air Tire using two method molding, molding machine transmission components design selection using mitsubishi J4 series servo motor and control system. Among them, the two-segment host pitch and rotary servo motor selection is the most typical, this paper on its design ideas and selection of a detailed discussion, for manufacturers to correctly select servo motor to provide reference.
\end{abstract}

Keywords: radial air tires; two-stage shaping host; servo motor; selection optimization

\section{Introduction}

Meridian Air Tire Molding machine is the key equipment for the manufacture of air tires, which is usually formed by two methods. In the process of molding machine design and manufacture, the precision positioning, rapid feedback and cycle control of molded semi-finished rubber parts are required, and the main application parts are: A section of host rotation, two segments with beam layer bondingdrum rotation, two section footwear winding head lifting and panning, Two segment host pitch and rotation, host rear pressure rotation/advance and retreat/division, etc. Among them, the two-segment host pitch and rotary servo motor selection is the most typical, the following on its design ideas and selection methods to discuss.

\section{1. process flow and equipment structure principle}

Company 16 20-Inch radial air tire two-time molding machine consists of a section of molding machine and twosegment molding machine. A molding machine is used for molding aeronautical meridian Fetal Body, the main adhesive components include lining layer, fiber cord body, wire ring, tire side, filler glue, shoulder pad glue, wear-resistant adhesive and body coating, curtain reinforcement layer, etc.; two-stage molding machine with beam layer bonding drum forwinding beam layer, bonding corrugated protective layer, FittingTire surface and other adhesive parts, Two-stage molding machine shapingDrum AdoptionNo capsule drum, by the left and right two chucks respectively installed in the molding machine spindle, external bushings on the chuck composition. The joint area is fitted with a PU ring to prevent compressed air leakage during training. The following focuses on the two-segment fetal billet shaping process and equipment structure principle.

\subsection{Process Flow}

In the two section of the host training drum, a section of the molding machine molded a good tire body in the adjustment of a flat width of the shaping chuck, the shape of the bulging drum rise, chuck lock the body mouth part. Compressed air through the molding machine hollow spindle to inflate the body, while the spindle pitch servo motor rotation, through the ball screw to drive the two cards to the middle of the closing, so that the body inflatable shaping, the formation of the basic outline of the tire. Then, the transmission ring will be clamped tread/belt layer composite parts transmitted and fitted to the surface of the tread, the spindle rotation, at the same time through the tread pressure roller,tire shoulder pressure roller, rear pressure roller combination rolling, the body, The composite parts with bundles are closely attached to the surface of the tread, and the tread is shaped and finished. After shaping and rolling, the gas in the fetus is discharged, the tire billet is detached from the shaping Chuck, and the tire billet is removed by the transfer ring. The entire training process processes are as follows: 
The chuck is divided into a flat width $\rightarrow$ placement of fetal body $\rightarrow$ Styling up and down the drum rise $\rightarrow$ low pressure inflatable $\rightarrow$ The chuck closes to the predetermined type $\rightarrow$ Transfer ring right shift $\rightarrow$ high pressure inflatable $\rightarrow$ chuck closed to styling position, ultra-shaping position $\rightarrow$ Transfer ring relaxation $\rightarrow$ Transfer ring left shift $\rightarrow$ tread, tire shoulder, rear pressure roller combination rolling $\rightarrow$ Passing ring discharge tire

During the training process, the tire body inflatable pressure gradually increased, from $0.05 \mathrm{MPa}, 0.1 \mathrm{Mpa}$ finally reached $0.18 \mathrm{MPa}$, the center line of the placenta does not move, the side of the fetal ring symmetrical shrinkage, Inflatable, fetal coil shrinkage, fetal expansion synchronized, the center line of the placenta and tread/belt layer composite parts of the center line coincide, each glue parts through the rear pressure combined pressure roller rolling tightly fit to form the shape of the fetal billet.

\subsection{Principle of equipment structure}

Two segment molding machine host pitch, rotation diagram as shown in Figure 1(overlooking):

(1) shaping distance mechanism

Two segment molding machine host pitch implementation process is: Mitsubishi HG-SR Series servo motor with MOTOREDUCE brand VB series Planetary reducer1 (Motor reducer under the spindle, the diagram will be removed from the motor, indicated by a dotted line) rotation, motor sprocket 2 drive sprocket8, two sprocket 8 Installed on two bidirectional ball screws, two bidirectional screw horizontal placement, front right spin, back end left, two pieces supporting screw nut12,13 Installing external bushings separately14 rear end Front bracket11 upper and spindle4 back end the rear bracket9 On.

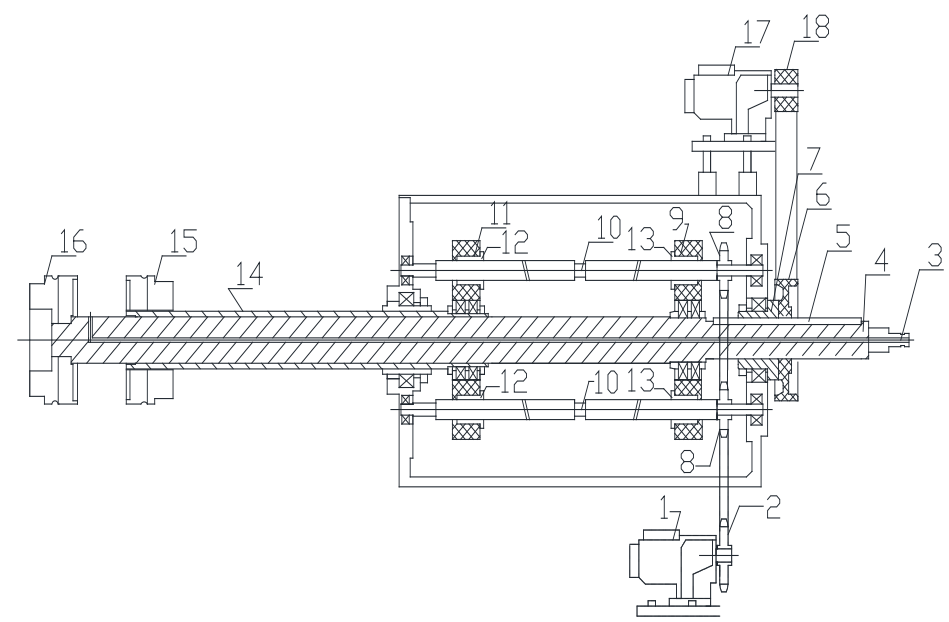

1-distance servo motor, reducer; 2-motor sprocket; 3-rotary joint; 4-spindle; 5-guide key; 6-large synchronous belt wheel; 7-guide seat; 8-ball screw sprocket; 9-ball screw rear bracket; 10-left and right ball screw; 11-ball screw front bracket; 12-Front ball screw Nut ; 13-rear ball screw nut; 14-outer bushing; 15-right Chuck; 16-left chuck; 17-Rotary servo motor, reducer; 18-small Synchronous belt wheel

Figure 1: two segment molding machine host pitch, rotation diagram

When the distance servo motor is turning in the direction, driving the sprocket 8 , the ball screw is rotated with the same turn, at this time, two front right-handed ball screws push the outer bushing14 Flattening shift, install the right chuck at the front end of the outer bushing 15 and pan forward at the same time; two rear left spin ball screws pull the spindle back and pan, mounted on the front end of the spindle left chuck16 pan backward at the same time. The two cards are panned in opposite directions, and the tire billet pitch is shaped. When the shaping servo motor rotates in the opposite direction, driving the sprocket8, the ball screw is rotated with the same turn, two front right-handed ball screws pull the outer bushing14 pan backward, right chuck15At the same time pan backward; two rear left spin ball screws push the spindle forward to pan, left chuck 16 pan forward at the same time. Two card disk back translation, to carry out the training drum adjustmentlevelingwide work.

(2) host rotating mechanism 
Two segment molding machine host rotation execution process is: Mitsubishi HG-SRSeries servo motor with MOTOREDUCE brand VBseries Planetary reducer1 7, the motor synchronous belt wheel18 drive the spindle synchronous belt wheel6rotation. Thespindle4 is supported by the bearing of the front seat and rear seat of the chassis, and the rear bearing is mounted on the guide seat7, and thesynchronous belt wheel 6 is fixed on the guide seat, the guide seat7and the spindle 4 are connected by the guide key5, and the spindle is in the guide groove make axial movement and drive torque through the key. The spindle4 and the outer bushing 14 also have a guide key connection when the rotating servo motor rotates, driving the spindle4, outer bushing14, shaping drum15/16, The fetal billet rotates together, and the combined rolling action is carried out.

Spindle 4and outer bushing14 have guide key connection, can carry on the left and right relative translation movement, rotate together when rotating; spindle4and guide seat7 also has the guide key join, can carry on the left and right relative translation movement, rotates together when rotating.

\section{Design selection process}

\subsection{Existing problems and preliminary verification}

After the Air Meridian two section molding machine is put into production and applied, the servo motor has several overload alarm phenomena in the process of pitch setting and rotary rolling, and the power of servo motor is judged preliminarily by empirical method and analogy method. First, based on the principle of investment minimization, the following verification is carried out:

(1) The host rotary servo motor, REDUCER (MitsubishiHG-SR502J 5KW,reducerVB-DR-140-005-S2-P1, speed ratio 1:5) with pitch servo motor (MitsubishiHG-SR352J 3.5KW,reducerVB-DR-180-010-S2-P1, Speed ratio1:10) Installation position interchange, at the same time the control system servo drive, cable, connector replacement, modify PLC control procedures, still appear pitch motor, rotating motor have overload alarm phenomenon.

Only consider the motor, reducer situation, the preliminary reasoning is as follows:

By formula:

$\mathrm{T}=\frac{9550 \mathrm{P}}{N_{e} \times i \times \eta}$

T--rated torque in formula N.m

$\mathrm{P}--$ rated power $\mathrm{KW}$

$\mathrm{N}_{\mathrm{e}}$--rated speed $\mathrm{r} / \mathrm{min}$

i --deceleration ratio

ๆ--reducer transmission efficiency, checkVB-140/VB-180Series Reducer samples, its efficiency are above 95\%.

Rated output torque in the non-braking, the same rated speed (2000r/min), the host pitch replacement motor, reducer after the output torque reduction, easier overload alarm, the host rotation replacement servo motor, reducer, improper selection, overload alarm.

(2) 2Motors, reducer back to the original installation position, the distance motorVBseries reducer from1:10 to 1:20, at the same time, the motor sprocket 2 from the original 32 teeth, changed to 26 teeth, So the adjustment of the mechanism deceleration ratioreached more than 2 times the original. In the process of fetal billet shaping, the rotation drive of the distance motor can make the tire billet reach the super-stereotyped position by the training bit, but in the super-stereotyped position combination rolling process, the servo motor can not maintain the positioning for a long time, the display display pitch spacing gradually increased, the motor alarm, the equipment can not move. After that, the motor is replaced with MitsubishiHG-SR352BJ 3.5KWwith electromagnetic brake servo motor, the situation has changed, but there will be motor overload alarm problem.

As a result of the preliminary verification, the selection of the distance servo motor needs to be re-demonstrated, and the selection of rotary servo motor is verified.

\subsection{Pitch servo motor selection verification}

(1) Relevant parameters: 
After consulting the relevant drawings and information, as follows:

Tire Billet quality $\mathrm{M}_{1}: 78 \mathrm{~kg}$

Spindle quality $\mathrm{M}_{2}: 280 \mathrm{~kg}$

External bushing quality $\mathrm{M}_{3}: 73 \mathrm{~kg}$

Left and right shaping drum mass $\mathrm{M}_{4}: 15 \mathrm{~kg}$

Ball screw mass $M_{\text {sg }}=24.2 \mathrm{~kg}$ pitch $P_{B}=8 \mathrm{~mm}$ nominal diameterD $D_{\text {sg }}$ take $60 \mathrm{~mm}$

Ball screw friction coefficient: $\mu_{1}$ take 0.02

Tire Billet rim plane width $915 \mathrm{~mm}$, predetermined position $880 \mathrm{~mm}$ stay 5 seconds, ultra-shaping location $430 \mathrm{~mm}$,training totaltime 42 seconds

Ball screw sprocket Tooth number $\mathrm{Z}_{1}=17$ mass $\mathrm{M}_{\mathrm{L} 1}=2.1 \mathrm{~kg}$, chain $16 \mathrm{~A}$

Motor sprocket Tooth number $\mathrm{Z}_{2}=26$ quality $\mathrm{M}_{\mathrm{L} 2}=4.8 \mathrm{~kg}$

Motor deceleration ratio is based on the original design to take $i_{1}=20$

VB180 reducer transmission efficiency take $\eta_{1}=90 \%$

Sprocket drive Efficiency $\eta_{2}=96 \%$

Transmission efficiency of ball screw $\eta_{3}=95 \%$

Ball screw positioning accuracy APC $0.01 \mathrm{~mm}$

(2) Servo motor speed

According to the actual production, the unilateral training pitch speed $\mathrm{V}$ control in $6.5 \mathrm{~mm} / \mathrm{s}$ is most suitable, the maximum speed of $8 \mathrm{~mm} / \mathrm{s}$, because the ball screw drive The shaping chuck at the same time parallel, the shape of the pitch speed of twice times the unilateral speed. The maximum speed of the servo motor is determined by the shaping speed, the screw pitch and the deceleration ratio of the transmission system, by the formula:

$\mathrm{N}_{\mathrm{e}} \geq \mathrm{N}=60 \frac{\mathrm{V}}{P_{B}} \times \mathrm{i}_{\mathrm{z}}$

N--Servo motor speed ,r/min

V--Tire billet shaping distance working speed, $\mathrm{mm} / \mathrm{s}$

$\mathrm{i}_{\mathrm{z}}$-Total deceleration ratio of the distance adjustment mechanism

Put $V=6.5 \mathrm{~mm} / \mathrm{s}, \mathrm{P}_{\mathrm{B}}=8 \mathrm{~mm}, \mathrm{i}_{\mathrm{z}}=\frac{\mathrm{Z} 1}{Z_{2}} \times \mathrm{i}_{1}=13.08$, get $\mathrm{N}=637.5 \mathrm{r} / \mathrm{min}$

Maximum speed $\mathrm{N}_{\max }=785 \mathrm{r} / \mathrm{min}$.

(3) Load inertia

The load inertia of the distance servo motor is the inertia generated by acceleration and deceleration during the shaping pitch. When the load inertia is relative to the motor inertia exceeding the load inertia ratio specified by the motor, the motor response characteristics become worse. In the training process of two-segment molding machine, in order to ensure the positioning accuracy and response characteristics, it is required that the load inertia $J_{Z}$ converted to the shaft end of the motor and the inertial $\mathrm{J}_{\mathrm{M}}$ ratio of the motor itself be within 4 times times range.

(1) 2 ball screw inertia converted to the shaft end of the motor:

$\mathrm{J}_{\mathrm{sg}}=\frac{2 J_{1}}{i_{z}^{2}}=\frac{2 M_{s g} D_{s g}^{2}}{8 i_{z}^{2}}$

To $\mathrm{J}_{\mathrm{SG}} \approx 1.27 \mathrm{~kg} \cdot \mathrm{cm}^{2}$

(2) 2 Ball screw sprocket inertia converted to the shaft end of the motor:

$\mathrm{J}_{\mathrm{L} 1}=\frac{2 J_{2}}{i_{Z}^{2}}=\frac{2 M_{L 1} D_{L 1}^{2}}{8 i_{Z}^{2}}$

Calculate $\mathrm{p}=25.4 \mathrm{~mm}$ pitch sprocket, estimate $\mathrm{D}_{\mathrm{L} 1}=\frac{p}{\sin \frac{180^{\circ}}{Z_{1}}}=138 \mathrm{~mm}$ by fractal circle diameter, and get $\mathrm{J}_{11} \approx 0.58 \mathrm{~kg} \cdot \mathrm{cm}^{2}$

(3) 1 motor sprocket inertia converted to the shaft end of the motor:

$\mathrm{J}_{\mathrm{L} 2}=\frac{J_{3}}{i_{1}^{2}}=\frac{M_{L 2} D_{L 2}^{2}}{8 i_{1}^{2}}$ 
Estimation by split circle diameter $\mathrm{D}_{\mathrm{L} 2}=\frac{p}{\sin \frac{180^{\circ}}{Z_{2}}}=211 \mathrm{~mm}$, get $\mathrm{J}_{\mathrm{L} 2} \approx 0.67 \mathrm{~kg} \cdot \mathrm{cm}^{2}$

(4) Inertia of axial moving parts:

$\mathrm{J}_{\mathrm{Y}}=\mathrm{M}_{\mathrm{Z}} \times\left(\frac{P_{B}}{2 \pi}\right)^{2}$

Where $\mathrm{M}_{\mathrm{Z}}$-The sum of the quality of the accessories such as the shape of the tire billet, the outer bushing, the spindle, the shaping drum and the bracket, take $500 \mathrm{~kg}$

Get $\mathrm{J}_{\mathrm{Y}} \approx 8.1 \mathrm{~kg} \cdot \mathrm{cm}^{2}$

(5) The moment of inertia of the reducer, check the sample of VB-DR-180-020-S2-P1 reducer, the moment of inertia is $\mathrm{J}_{\mathrm{j} 1}=7.3 \mathrm{~kg} \cdot \mathrm{cm}^{2}$

(6) The sum of the inertia of the inner ring of 4 bearings on 2 ball screws is smaller than that of the sprocket and ball screw, and the inner ring inertia of the bearing is small.

$\mathrm{J}_{\mathrm{Z}}=\mathrm{J}_{\mathrm{SG}}+\mathrm{J}_{11}+\mathrm{J}_{12}+\mathrm{J}_{\mathrm{Y}}+\mathrm{J}_{\mathrm{j} 1} \approx 18.0 \mathrm{~kg} \cdot \mathrm{cm}^{2}$

Check Mitsubishi HG-SR352J servo motor sample, rated speed of 2000r/min, maximum speed of 3000r/min, motor rotor inertia $\mathrm{J}_{\mathrm{M}}=88.2 \mathrm{~kg} \cdot \mathrm{cm}^{2}$, far greater than MotorsShaftEnd LoadInertia, Load inertia matching.

(4) Load torque

The load torque of the distance motor refers to the working driving force, friction and acceleration torque of the mechanical moving part during the training pitch, and after a working cycle of the two-segment molding machine, the motor is shut down for a long time, requiring the load torque $T_{L} \leq T_{e}$ can be.

(1) Load torque generated by internal pressure

In the horizontal axial position of the training process, the axial load $\mathrm{F}_{\mathrm{a}}$ of the shape internal pressure on the left shaping drum and the right shaping drumcan estimate the load torque converted to the shaft end of the motor by the left and right ball screws, as shown in Figures 2 and 3:

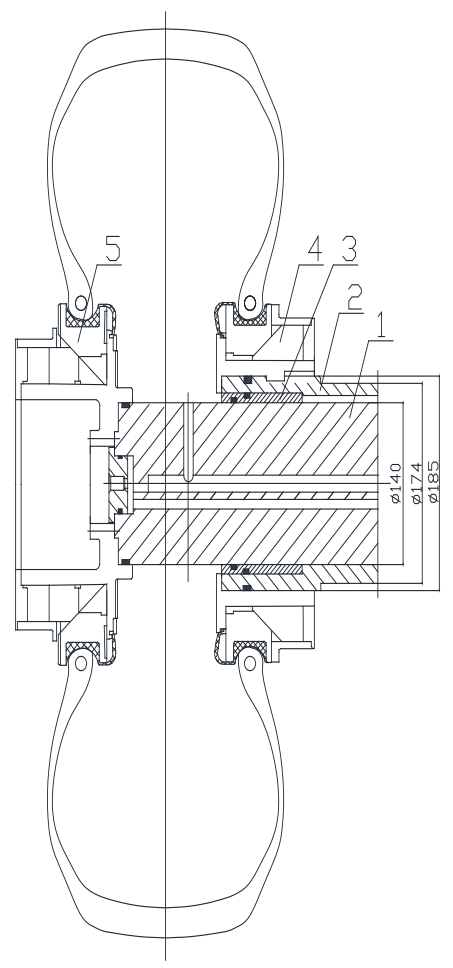

1- spindle; 2-outer bushing; 3-bearing; 4-right shaping drum; 5-left shaping drum

Figure 2: shaping drum shrinkage structure diagram 


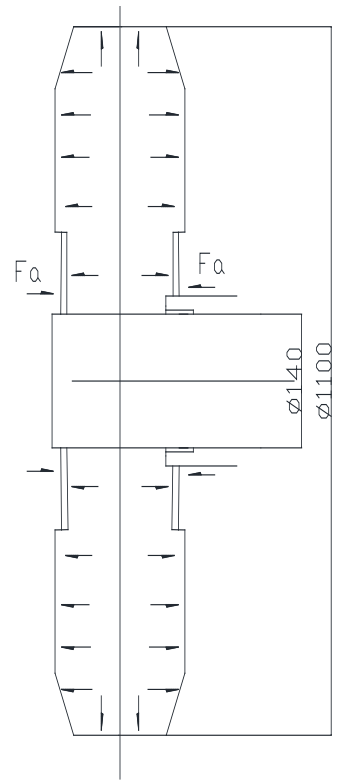

Fig. 3: Analysis of inflatable force of Tire Billet

When the stereotype is in an ultra-stereotyped position, at this point, the internal pressure is the largest, resulting in the largest axial load, $2 \mathrm{~F}_{\mathrm{a}}$

$\mathrm{F}_{\mathrm{a}}=\frac{\pi\left(D_{t}{ }^{2}-d_{t}^{2}\right) \times 10^{-6}}{4} \times 0.18 \times 10^{6}$

$\mathrm{D}_{\mathrm{t}}$--Maximum diameter of fetal billet cavity, $1100 \mathrm{~mm}$

$\mathrm{d}_{\mathrm{z}}$-shape drum spindle outer diameter, $140 \mathrm{~mm}$

By the above parameters, get the $\mathrm{F}_{\mathrm{a}} \approx 168203.5 \mathrm{~N}$

Load torque generated by motor shaft end $\mathrm{T}_{\mathrm{ny}}$ :

$\mathrm{T}_{\mathrm{ny}}=\frac{2 F_{a} P_{B}}{2 \pi \eta_{1} \eta_{2} \eta_{3} i_{z}}$

Substitute the above calculated values, $\mathrm{T}_{\mathrm{ny}} \approx 39.9 \mathrm{Nm}$

Friction load torque $\mathrm{T}_{\mu}$, generated by friction of the bearing

$\mathrm{T}_{\mu}=\frac{2 F_{a} P_{B}}{2 \pi \eta_{1} \eta_{2} \eta_{3} i_{z}}$

$\mathrm{F}_{\mu 0}$--friction of the load state bearing, $\mathrm{N}, \mathrm{F}_{\mu 0}=\mu \mathrm{F}_{\mathrm{z}} \mathrm{g}$

(2) Friction coefficient of $\mu$--copper tile and steel, take $\mu=0.15$

$\mathrm{F}_{\mathrm{z}}$-The total friction caused by the relative motion of the outer bushing and spindle, $\mathrm{N}$

As shown in Figure 1, during the mainframe pitch, the spindle and the outer bushing are relatively panned, while bearing the weight of the cantilever shaft support tire billet, the contact bearing of each component is sliding friction, the force size changes, according to the two section of the main spindle length, support point position, cantilever length, force direction and other related factors, the estimated total friction force $F_{Z}$ at 2 4 times times the $M_{z}$ value, where the mean value of 3 times is calculated, the known value is taken into the $\mathrm{T}_{\mu} \approx 0.26 \mathrm{Nm}$

(3) Additional pre-tightening torque $\mathrm{T}_{\mathrm{f}}$, generated by screw pretightening Force

The ball screw drive with fetal billet shaping does not allow for reverse clearance, requires high positioning accuracy and axial stiffness, and the ball screw should be pre-set to pre-tighten the force. In this example, the ball screw is balanced by axial force, and the axial load is approximately1/20 1/40 of the rated dynamic loadof the ball screw. Check the FFZD6308 ball screw rated dynamic load for $40 \mathrm{KN}$, take the preload $\mathrm{F}_{\mathrm{f}}=2 \mathrm{KN}$, calculate 2 ball screws, there are:

$\mathrm{T}_{\mathrm{f}}=\frac{2 K F_{f} P_{B}}{2 \pi \eta_{1} \eta_{2} i_{z}}$

K-ball screw torque coefficient $\mathrm{k}=0.05 \sqrt{\tan \beta}$, beta for ball screw guide Angle 
$\tan \beta=\frac{P_{B}}{\pi D_{a}}, \mathrm{D}_{\mathrm{a}}$ is the roller diameter, check the ball screw sample $\mathrm{D}_{\mathrm{a}}=4.762 \mathrm{~mm}$, get $\mathrm{k}=0.037$

$\mathrm{F}_{\mathrm{f}}$--pretightening force of ball screw nut pair, $\mathrm{N}$

Substitute known values for $\mathrm{T}_{\mathrm{f}} \approx 0.017 \mathrm{Nm}$

(4) Maximum Load torque

Molding machine Shape drum no-load pitch process, fast forward maximum load torque $\mathrm{T}_{\mathrm{KJ}}$ :

$\mathrm{T}_{\mathrm{KJ}}=\mathrm{T}_{\mu}+\mathrm{T}_{\mathrm{f}} \approx 0.28 \mathrm{Nm}$

The maximum load torque $\mathrm{T}_{\mathrm{GJ}}$ during the formation of the tire billet of the molding machine:

$\mathrm{T}_{\mathrm{GJ}}=\mathrm{T}_{\text {ny }}+\mathrm{T}_{\mathrm{f}} \approx 39.9 \mathrm{Nm}$

$\mathrm{T}_{\mathrm{e}} \geq \operatorname{MAX}\left\{T_{K J}, T_{G J}\right\}=39.9 \mathrm{Nm}$

(5) Maximum acceleration torque required for motor shaft end

When the no-load accelerates the start, The training process is generated by the linear acceleration law of the Torque $\mathrm{T}_{\mathrm{ap}}$ :

$\mathrm{T}_{\mathrm{ap}}=\frac{2 \pi N_{\max }\left(J_{M}+J_{Z}\right) \times 10^{-4} \times\left(1-e^{-k_{S} t_{a}}\right)}{60 t_{a}}$

$\mathrm{N}_{\max }$-The maximum speed of the motor corresponding to the load-empty shaping drum moving at the fastest speed, $r /$ min $\mathrm{J}_{\mathrm{M}}$-rotor inertia of the motor, $\mathrm{kg} \cdot \mathrm{cm}^{2}$

$\mathrm{J}_{\mathrm{z}}$-Motor total load inertia, $\mathrm{kg} \cdot \mathrm{cm}^{2}$

$\mathrm{t}_{\mathrm{a}}=3 / \mathrm{K}_{\mathrm{s}}, \mathrm{k}_{\mathrm{s}}$ is the position ring gain of the servo system, $\mathrm{Hz}$, usually take $\mathrm{k}_{\mathrm{s}}=8 \sim 25 \mathrm{~Hz}$, servo motor in position control mode. Pulse to add deceleration slope, molding machine training requirements positioning accuracy control in $0.1 \mathrm{~mm}$ can be, the desirability of $\mathrm{k}_{\mathrm{s}}=$ more than $\mathrm{Hz}$, get $\mathrm{t}_{\mathrm{a}}=0.3 \mathrm{~s}$

Substitute the above values for $\mathrm{T}_{\mathrm{ap}} \approx 2.8 \mathrm{Nm}$

In the tire billet booking process, at this time there is a 5-second time pause process, and began to run until the training, ultra-stereotyped position, the motor in the load acceleration state, the resulting acceleration torque $\mathrm{T}_{\mathrm{ad}}$ :

$\mathrm{T}_{\mathrm{ad}}=\frac{2 \pi N\left(J_{M}+J_{Z}\right) \times 10^{-4}}{60 t_{a}}$

$\mathrm{N}$-maximumshaping speed when the motor speed, for the motor operating speed, $\mathrm{r} / \mathrm{min}$

$\mathrm{t}_{\mathrm{a}}=1 / \mathrm{k}_{\mathrm{v}}, \mathrm{k}_{\mathrm{v}}$ for servo systemspeed loopgain, Hz, satisfying formula:positionringgain $(1 / \mathrm{s}) \leq 2 * \pi *$ speed ringGain $(\mathrm{Hz}) / 4$, take $\mathrm{k}_{\mathrm{V}}=2 \mathrm{k}_{\mathrm{S}}=20 \mathrm{~Hz}$, get $\mathrm{t}_{\mathrm{a}}=0.05 \mathrm{~s}$

Substitute the above values for $\mathrm{T}_{\mathrm{ad}} \approx 14.2 \mathrm{Nm}$

(6) Maximum torque Ta required on the motor shaft:

No-load startup acceleration torque $\mathrm{T}_{\mathrm{akj}}=\mathrm{T}_{\mathrm{ap}}+\mathrm{T}_{\mu}+\mathrm{T}_{\mathrm{f}} \approx 2.1 \mathrm{Nm}$

Styling speed change accelerate torque $\mathrm{T}_{\mathrm{aGJ}}=\mathrm{T}_{\mathrm{ad}}+\mathrm{T}_{\mathrm{ny}}+\mathrm{T}_{\mathrm{f}} \approx 54.1 \mathrm{Nm}$

Maximum equivalent load torque $\mathrm{T}_{\mathrm{dx}}=\operatorname{MAX}\left\{T_{a K J}, T_{a G J}\right\}=54.1 \mathrm{Nm}$

(7) Molding machine Training process, servo motor in intermittent working state, no need to start frequently, braking, can not consider the servo motor in a cycle of torque mean square root value.

Mitsubishi HG-SR352BJ Servo rated torque $16.7 \mathrm{~nm}$, maximum torque $50.1 \mathrm{~nm}$, obviously, can not meet (13), (18) type requirements, the need for servo motor,deceleration machine re-selection.

According to the above relevant parameters, choose Mitsubishi Servo Motor Reducer HG-SR702BG1 type, 7.0KW, rated speed $\mathrm{N}_{\mathrm{e}} 2000 \mathrm{r} / \mathrm{min}$, maximum speed $3000 \mathrm{r} / \mathrm{min}$, rated torque $33.4 \mathrm{Nm}$, maximum torque $100 \mathrm{Nm}$, motor inertia $161 \mathrm{~kg}$. $\mathrm{cm}^{2}$, choose Mitsubishi Reducer Speed ratio 1:29, $\mathrm{i}_{1}^{\prime}=29$ reducer Model: KB-180-29-S2-P2 $\mathrm{J}_{\mathrm{J} 1}{ }^{\prime}=15.2 \mathrm{~kg} \cdot \mathrm{cm}^{2}, \mathrm{Reducer}$ transmission efficiency: $\eta_{1}{ }^{\prime}=94 \%$

According to the above formula, you can get:

$i_{Z}^{\prime}=\frac{\mathrm{Z}_{1}}{Z_{2}} \times \mathrm{i}_{1}^{\prime} \approx 19$

$\mathrm{N}^{\prime}=926.3 \mathrm{r} / \mathrm{min}$

$N_{\max }^{\prime}=1140 \mathrm{r} / \mathrm{min}$ 


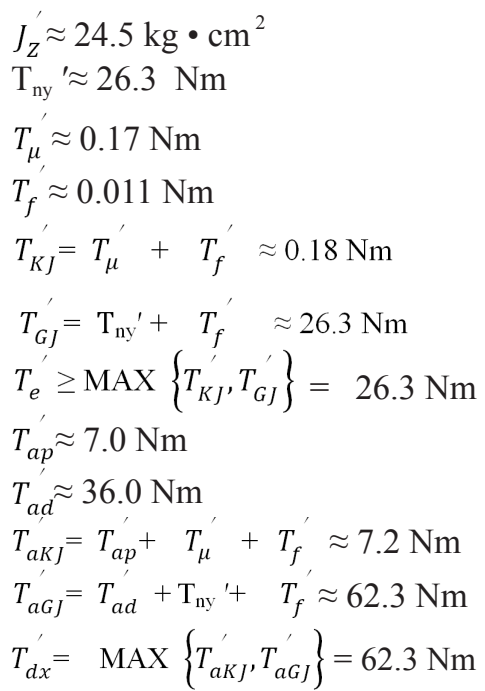

From the above calculation data can be seen :

Motor operating speed is less than motor rated speed, $\mathrm{N}^{\prime}<2000 \mathrm{r} / \mathrm{min}$

The maximum working speed is less than the maximum motor speed, $N_{\max }^{\prime}<3000 \mathrm{r} / \mathrm{min}$

The load inertia of the motor shaft end is much smaller than the motor inertia, $J_{z}^{\prime}<161 \mathrm{~kg} \bullet \mathrm{cm}^{2}$

The working torque is less than the rated torque of the motor, $T_{e}^{\prime}<33.4 \mathrm{Nm}$

The maximum operating torque of the load is less than the maximum torque of the motor, $T_{d x}^{\prime}<100 \mathrm{Nm}$

Through the verification, two-segment molding host distance motor re-selection qualified.

\subsection{Rotary servo Motor selection Verification}

(1) Relevant parameters:

Consult the relevant drawings and materials as follows:

Servo motor model: HG-SR502J 5KW, reducer VB-DR-140-005-S2-P1 deceleration ratio $\mathrm{i}_{2}=5$

Servo synchronous Belt Wheel: 32-14M, diameter $\mathrm{d}_{1}=142.6 \mathrm{~mm}$, number of teeth $\mathrm{z}_{\mathrm{d} 11}=32$, Mass $\mathrm{M}_{\mathrm{d} 11}=7.7 \mathrm{~kg}$

Spindle Synchronous Belt Wheel: $80-14 \mathrm{M}$, diameter $\mathrm{d}_{2}=356.5 \mathrm{~mm}$ tooth number $\mathrm{z}_{\mathrm{d} 12}=80$, $\operatorname{mass} \mathrm{M}_{\mathrm{d} 22}=24.3 \mathrm{~kg}$

Friction coefficient between roller wheel and adhesive parts during tire billet combination rolling: $\mu_{\mathrm{x}}$ take 0.20

Tire Billet combination Rolling working speed: $\mathrm{N}_{\mathrm{x}}=45 \mathrm{r} / \mathrm{min}$, maximum speed $\mathrm{N}_{\mathrm{xmax}}=65 \mathrm{r} / \mathrm{min}$

During the combination rolling process of the tire billet, the pressure change process of the rear pressure cylinder is as: 0.25

$\mathrm{Mpa} \rightarrow 0.3 \mathrm{MPa} \rightarrow 0.35 \mathrm{MPa} \rightarrow 0.25 \mathrm{MPa}$, tire shoulder pressure roller pressure $: 0.4 \mathrm{MPa}$, tread press roller pressure: $0.4 \mathrm{MPa}$

VB140 reducer transmission efficiency take $\eta_{\mathrm{x} 1}=95 \%$

Synchronous belt drive Efficiency $\eta_{\mathrm{x} 2}=98 \%$

(2) rotating servo motor speed

The rotation speed of the rotating servo motor of the two-segment molding machine is determined by the rotation speed of the tire billet and the deceleration ratio of the transmission system, by the formula:

$\mathrm{N}_{\mathrm{M}}=\mathrm{N}_{\mathrm{x}} \times \frac{\mathrm{z}_{d l 2}}{z_{d l 1}} \times \mathrm{i}_{2}$

The known data is included in the $\mathrm{N}_{\mathrm{M}}=562.5 \mathrm{r} / \mathrm{min}$, themaximum speed $\mathrm{N}_{\mathrm{Mmax}}=812.5 \mathrm{r} / \mathrm{min}$.

(3) Load inertia

The load inertia of rotary servo motor of molding machine is the inertia produced during the acceleration and deceleration of the tire billet rolling process. During the combined rolling rotation of the two-segment molding machine, the load inertia $\mathrm{J}_{\mathrm{XZ}}$, which is required to be converted to the shaft end of the motor, is within 4 times times the ratio of the inertial $\mathrm{J}_{\mathrm{Mx}}$ of the motor itself .

(1) Synchronous belt wheel inertia of servo motor converted to motor shaft end:

$\mathrm{J}_{\mathrm{d} 11}=\frac{M_{d l 1} d_{1}^{2}}{8 i_{2}^{2}}$ 
Get $\mathrm{J}_{\mathrm{dl} 1} \approx 7.8 \mathrm{~kg} \cdot \mathrm{cm}^{2}$

(2) The Spindle synchronous belt wheel inertia converted to the shaft end of the motor:

$\mathrm{J}_{\mathrm{d} 12}=\frac{M_{d l 2} d_{2}^{2}}{8 i_{x z}^{2}}$

$\mathrm{i}_{\mathrm{xz}}=\frac{z_{d l 2}}{z_{d l 1}} \times \mathrm{i}_{2}=12.5$, get $\mathrm{J}_{\mathrm{d} 12} \approx 24.7 \mathrm{~kg} \bullet \mathrm{cm}^{2}$

(3) Spindle, outer bushing inertia: In the tire billet combination rolling process, the spindle, external bushing together rotation, take $\mathrm{M}_{\mathrm{zz}}=400 \mathrm{~kg}$

$\mathrm{J}_{z z}=\frac{M_{z z} D_{z}^{2}}{8 i_{x z}^{2}}$

Take $\mathrm{D}_{\mathrm{z}}=16 \mathrm{~cm}$, get $\mathrm{J}_{z z} \approx 81.9 \mathrm{~kg} \cdot \mathrm{cm}^{2}$

(4) Shaping Drum Inertia:

$\mathrm{J}_{\mathrm{g}}=\frac{M_{g}\left(D_{g}^{2}+d_{z}^{2}\right)}{8 i_{x z}^{2}}$

$\mathrm{M}_{\mathrm{g}}=30 \mathrm{~kg}, \mathrm{~d}_{\mathrm{z}}=14 \mathrm{~cm}$, take $\mathrm{D}_{\mathrm{g}}=40 \mathrm{~cm}$, get $\mathrm{J}_{\mathrm{g}} \approx 43.1 \mathrm{~kg} \bullet \mathrm{cm}^{2}$

(5) The moment of inertia of the reducer, check the sample of VB-DR-140-005-S2-P1 reducer, the moment of inertia is:

$\mathrm{J}_{\mathrm{j} 2}=7.42 \mathrm{~kg} \cdot \mathrm{cm}^{2}$

(6) Rotation inertia of tire billet

The tire billet model figure is shown in Figure 3, the total mass of the placenta is $78 \mathrm{~kg}$, and the placenta is divided into three parts, left, middle and right, and the quality of $\mathrm{M}_{5}=24 \mathrm{~kg}, \mathrm{M}_{6}=30 \mathrm{~kg}, \mathrm{M}_{5}=24 \mathrm{~kg}$, it is estimated respectively on both sides of the fetal shoulder. the left and right two parts are similar to hollow cylinders to calculate the rotational inertia, the middle part is different hollow cylinders, the sum of which is the moment of inertia of the whole fetal billet.

$\mathrm{J}_{\mathrm{t}}=\frac{\frac{1}{3} M_{5}\left(d_{t}^{2}+D_{t}^{2}\right) \times 2+\frac{1}{8} M_{6}\left(D_{t}^{2}+D_{3}^{2}\right)}{i_{x z}^{2}}$

$\mathrm{M}_{5}=24 \mathrm{~kg}, \mathrm{M}_{6}=30 \mathrm{~kg}, \mathrm{~d}_{\mathrm{t}}=50.4 \mathrm{~cm}, \mathrm{D}_{\mathrm{t}}=110 \mathrm{~cm}, \mathrm{D}_{3}=121 \mathrm{~cm}$, get $\mathrm{J}_{\mathrm{t}} \approx 1204.0 \mathrm{~kg} \bullet \mathrm{cm}^{2}$

(7) The inertia of the inner ring of the rotating bearing on the spindle is very small relative to the spindle inertia and is negligible here.

$\mathrm{J}_{\mathrm{xz}}=\mathrm{J}_{\mathrm{d} 11}+\mathrm{J}_{\mathrm{d} 12}+\mathrm{J}_{\mathrm{zz}}+\mathrm{J}_{\mathrm{g}}+\mathrm{J}_{\mathrm{j} 2}+\mathrm{J}_{\mathrm{t}} \approx 1368.9 \mathrm{~kg} \cdot \mathrm{cm}^{2}$

Check Mitsubishi HG-SR502J servo motor sample, rated speed of 2000r/min, maximum speed of 3000r/min, motor rotor inertia $99.7 \mathrm{~kg} \cdot \mathrm{cm}^{2}$, motor inertia ratio: $\mathrm{J}_{\mathrm{xz}} / \mathrm{J}_{\mathrm{Mx}}=13.7$ times, well beyond the motor end load inertia 4 times times range.

(4) Load torque

Rotating servo motor load torque refers to the motor itself acceleration torque, load acceleration torque and normal operation of the required torque, molding machine combined rolling process, servo motor in a long time continuous working state, no need to start frequently, braking, do not consider the servo motor A periodic torque of the mean square root value, But to ensure that the load torque $\mathrm{T}_{\mathrm{Lx}} \leq 0.8 \mathrm{~T}_{\mathrm{Mx}}$

(1) Accelerated torque of the motor itself $\mathrm{T}_{\mathrm{x} 1}$

$\mathrm{T}_{\mathrm{x} 1}=\mathrm{J}_{\mathrm{mx}} \times \alpha_{\mathrm{mx}}=\frac{2 \pi N_{M \max } J_{M x} \times 10^{-4}}{60 t_{a x}}$

In the speed control mode, the rotary servo motor operates according to the acceleration and deceleration time inside the drive, considering the large inertia of the tire billet, the acceleration and deceleration time can be extended appropriately. Take $\mathrm{t}_{\mathrm{ax}}=10 / \mathrm{k}_{\mathrm{sx}}, \mathrm{k}_{\mathrm{sx}}$ Position Ring gain for servo system, Hz, usually take $\mathrm{k}_{\mathrm{sx}}=8 \sim 25 \mathrm{~Hz}$, take $\mathrm{k}_{\mathrm{sx}}=10 \mathrm{~Hz}$, Get $\mathrm{t}_{\mathrm{ax}}=1.0 \mathrm{~s}$ Substitute the above parameters for $\mathrm{T}_{\mathrm{x} 1}=0.85 \mathrm{Nm}$

(2) Load Acceleration Torque $\mathrm{T}_{\mathrm{x} 2}$

$\mathrm{T}_{\mathrm{x} 2}=\frac{2 \pi N_{M \max } J_{X \times} \times 10^{-4}}{60 t_{a x} \eta_{x 1} \eta_{x 2}}$

Substitute known values for $\mathrm{T}_{\mathrm{x} 2} \approx 12.5 \mathrm{Nm}$

(3) Torque $T_{x 3}$ required for normal operation, generated by combined rolling

After the completion of the fetal billet training, in two segments of the mainframe, the use of tread pressure roller, 
tireShoulder pressure roller, rear pressure roller on the tire billet adhesive parts for rolling. Tread Roller cylinder DSBC80-560-PPVA-N3, 1 group; tire shoulder Roller cylinder DSBC-80-600-PPVA-N3, 1 group; rear pressure roller cylinder ADVU-80-80-A-P-A, 2 groups; tread roller andtire Shoulder pressure roller different action, a certain period of time, there is a tireShoulder pressure roller (or tread pressure roller) and the rear pressureRoller simultaneousaction process. As shown in Figure 4, considering the number of cylinders, cylinder diameter and other factors, the maximum rolling pressure appearsin thetireShoulder pressure roller(or tread pressure roller) and the rear pressureroller at the same time The period of action, at this time, the rear pressure gaspressureis up to $0.35 \mathrm{MPa}$.

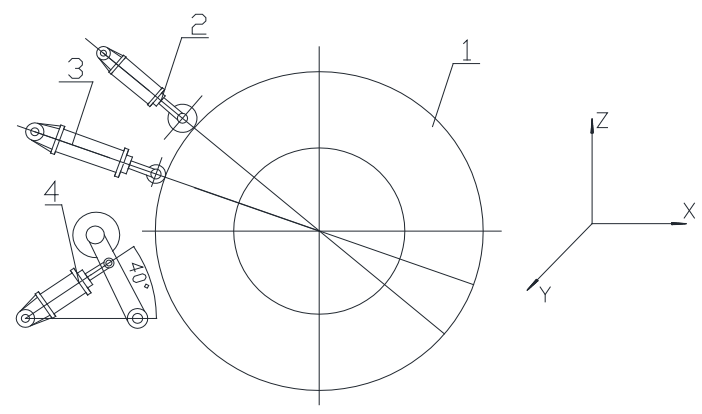

1-Fetal billet; 2-tread pressure roller; 3-tire shoulder pressure roller; 4-Rear Press Roller

Figure 4: Styling combination pressure Roller diagram

$\mathrm{T}_{x 3}=\frac{\mu_{x} F_{x} \times \frac{D_{3}}{2}}{i_{x z} \eta_{x 1} \eta_{x 2}}$

$\mu_{x}$ - Combination pressure roller and tire billet rolling friction coefficient, take 0.20

$F_{x}-$ The maximum pressure force of the combined pressure roller on the centerline of the spindle, $\mathrm{N}$; it is equal to the joint force of the tireShoulder pressure roller andthe rear pressure roller.

$F_{x}=\mathrm{F}_{\mathrm{i}}+2 \times \mathrm{F}_{\mathrm{h}} \cos 40$

$=\frac{\pi}{4} \times 0.08^{2} \times 0.4 \times 10^{6}+2 \times \frac{\pi}{4} \times 0.08^{2} \times 0.35 \times 10^{6} \times \cos 40$

$=4703.6 \mathrm{~N}$

$\mathrm{D}_{3}$-Outer diameter of tire billet, $1.21 \mathrm{~m}$

The known value, $\mathrm{T}_{\mathrm{x} 3} \approx 48.9 \mathrm{Nm}$, which is the working torque of the servo motor.

(4) Maximum load torque

$\mathrm{T}_{\mathrm{xmax}}=\mathrm{T}_{\mathrm{x} 1}+\mathrm{T}_{\mathrm{x} 2}+\mathrm{T}_{\mathrm{x} 3} \approx 62.3 \mathrm{Nm}$

Mitsubishi HG-SR502J servorated torque $23.9 \mathrm{Nm}$, maximum torque $71.6 \mathrm{~nm}$, obviously, can not meet the requirements of (27), at the same time, the motor load inertia ratio far beyond the requirements of not more than 4 times times, the servo motor reducer needs to be re-selected.

According to the above relevant parameters, select Mitsubishi Servo Motor reducer, the motor reducer deceleration ratio from 1:5 to $1: 17$, rated torque $23.9 \mathrm{Nm}$, maximum torque $71.6 \mathrm{Nm}$, motor inertia $\mathrm{J}_{\mathrm{Mx}}{ }^{\prime}=99.7 \mathrm{~kg} \cdot \mathrm{cm}^{2}$, reducer speed ratio 1:17, reducer model: KB180-17-S2-P2, reducer transmission efficiency $\eta_{\mathrm{x} 1}{ }^{\prime}=94 \%$

To re-account the above values, you must:

$\mathrm{N}_{\mathrm{M}}{ }^{\prime}=1912.5 \mathrm{r} / \mathrm{min}$, maximum velocity $\mathrm{N}_{\mathrm{Mmax}}{ }^{\prime}=2762.5 \mathrm{r} / \mathrm{min}$ 。

$\mathrm{J}_{\mathrm{d} 11}{ }^{\prime} \approx 0.67 \mathrm{~kg} \cdot \mathrm{cm}^{2}$

$\mathrm{J}_{\mathrm{d} 12}{ }^{\prime} \approx 2.1 \mathrm{~kg} \cdot \mathrm{cm}^{2}$

$\mathrm{J}_{\mathrm{zz}}{ }^{\prime} \approx 7.08 \mathrm{~kg} \cdot \mathrm{cm}^{2}$

$\mathrm{J}_{\mathrm{g}}{ }^{\prime} \approx 3.7 \mathrm{~kg} \cdot \mathrm{cm}^{2}$

$\mathrm{J}_{\mathrm{J} 2},=15.2 \mathrm{~kg} \cdot \mathrm{cm}^{2}$ (check Mitsubishi Servo motor REDUCER sample)

$\mathrm{J}_{\mathrm{t}}{ }^{\prime}=104.2 \mathrm{~kg} \cdot \mathrm{cm}^{2}$

$\mathrm{J}_{\mathrm{xz}}{ }^{\prime} \approx 133 \mathrm{~kg} \cdot \mathrm{cm}^{2}$ 
Check Mitsubishi HG-SR502J servo motor sample, rated speed of 2000r/min, maximum speed of 3000r/min, motor rotor inertia $\mathrm{J}_{\mathrm{Mx}}{ }^{\prime}=99.7 \mathrm{~kg} \cdot \mathrm{cm}^{2}$, Themotor inertia ratio is: $\mathrm{J}_{\mathrm{xz}}{ }^{\prime} / \mathrm{J}_{\mathrm{Mx}}{ }^{\prime}=1.33$ times, well below the motor end load Inertia 4 times times range, load inertia matching.

$\mathrm{T}_{\mathrm{x} 1}{ }^{\prime} \approx 2.88 \mathrm{Nm}$

$\mathrm{T}_{\mathrm{x} 2}{ }^{\prime}=4.17 \mathrm{Nm}$

$\mathrm{T}_{\mathrm{x} 3}{ }^{\prime} \approx 14.5 \mathrm{Nm}$

$\mathrm{T}_{\mathrm{Mx}}{ }^{\prime} \approx 21.6 \mathrm{Nm}$

Mitsubishi HG-SR502J Servo motor rated torque $23.9 \mathrm{~nm} 0.8$ times times greater than the load torque $\mathrm{T}_{\mathrm{x} 3}{ }^{\prime} 14.5 \mathrm{Nm}$, Motor Maximum torque $71.6 \mathrm{~nm}$ greater than maximum load torque $\mathrm{T}_{\mathrm{MX}}{ }^{\prime} 21.6 \mathrm{Nm}$, For the host rotating servo motordecelerationMachine to re-qualified selection.

\section{2-segment Molding machine host rotation and shaping servo motor selection Summary}

Two segment molding machine host re-selection replacement servo motor, reducer process, some selection parameters are summarized, such as Table 1:

The key point of selection of servo motor for two-segment molding machine is the calculation of load torque, and the selection of Rotary servo motor has a large load inertia. The above two sets of calculated servo motor, reducer, as well as re-alignment motor servo system control drive, cable, connector selection, installation in place and modify the corresponding PLC program, after 2 consecutive months of production, there are no problems, in the production practice has been fully verified.

\section{Conclusion}

The selection design of host pitchandrotary servo motor in radial Air Tire two-section molding machine is a relatively complex design and calculation process, which involves many disciplines of mechanical design and manufacture, including mechanical transmission, kinetic energy conservation Conversion, mechanical analysis, Electrical control and so on. In the process of production practice, the efficient and smooth operation of equipment is the practice test process of design and manufacture, and the applicability audit process of special working conditions on site. Equipment manufacturers can draw lessons from this, design and develop suitable for high-performance radial air tire molding key manufacturing equipment.

Table 1: two-segment molding machine host pitch and rotary servo motor selection Summary table

\begin{tabular}{|c|c|c|c|c|}
\hline $\begin{array}{l}\text { Serial } \\
\text { number }\end{array}$ & Category & Host Styling Pitch Servo motor & Host rotary Rolling Servo motor & Note \\
\hline 1 & $\begin{array}{l}\text { Replacement } \\
\text { of front motor, } \\
\text { reducer model }\end{array}$ & $\begin{array}{l}\text { HG-SR352BJ } \\
\text { VB-DR-180-020-S2-P1 }\end{array}$ & $\begin{array}{l}\text { HG-SR502J } \\
\text { VB-DR-140-005-S2-P1 }\end{array}$ & \\
\hline 2 & $\begin{array}{l}\text { Selection Criteria } \\
\text { for conformity } \\
\text { determination }\end{array}$ & \multicolumn{2}{|c|}{$\begin{array}{l}\text { (1) Continuous working torque }<\text { Servo motor rated } \\
\text { torque }(0.8 \text { times times special case) } \\
\text { (2) Instantaneous maximum torque }<\text { servo motor } \\
\text { Maximum torque (acceleration) } \\
\text { (3) Inertial ratio }<\text { The inertia ratio specified by the motor ( } 4 \text { times) } \\
\text { (4) Continuous working speed }<\text { Motor rated Speed }\end{array}$} & \\
\hline 3 & $\begin{array}{l}\text { Related Motor } \\
\text { parameters }\end{array}$ & $\begin{array}{l}\text { (1) Rated Speed } 2000 \mathrm{r} / \mathrm{min} \\
\text { (2) Maximum Speed } 3000 \mathrm{r} / \mathrm{min} \\
\text { (3) Inertial } 88.2 \mathrm{~kg} \cdot \mathrm{cm}^{2} \\
\text { (4) rated torque } 16.7 \mathrm{Nm} \text {, } \\
\text { maximum torque } 50.1 \mathrm{Nm}\end{array}$ & $\begin{array}{l}\text { (1) rated Speed } 2000 \mathrm{r} / \mathrm{min} \\
\text { (2) Maximum speed } 3000 \mathrm{r} / \mathrm{min} \\
\text { (3)inertia } 99.7 \mathrm{~kg} \cdot \mathrm{cm}^{2} \\
\text { (4) rated torque } 23.9 \mathrm{Nm} \text {, } \\
\text { maximum torque } 71.6 \mathrm{Nm}\end{array}$ & \\
\hline 4 & $\begin{array}{l}\text { Load condition } \\
\text { converted to } \\
\text { the shaft end } \\
\text { of the motor }\end{array}$ & $\begin{array}{l}\text { (1) Speed } 637.5 \mathrm{r} / \mathrm{min} \\
\text { (2) Maximum Speed } 785 \mathrm{r} / \mathrm{min} \\
\text { (3) Inertial } \mathrm{Kg} \cdot \mathrm{cm}^{2} \\
\text { (4) working torque } 39.9 \mathrm{Nm} \text {, } \\
\text { maximum torque } 54.1 \mathrm{Nm}\end{array}$ & $\begin{array}{l}\text { (1) Speed } 562.5 \mathrm{r} / \mathrm{min} \\
\text { (2) Maximum Speed } 812.5 \mathrm{r} / \mathrm{min} \\
\text { (3) Inertial } 1368.9 \mathrm{~kg} \cdot \mathrm{cm}^{2} \\
\text { (4) working torque } 51.6 \mathrm{Nm} \text {, } \\
\text { maximum torque } 65.7 \mathrm{Nm}\end{array}$ & \\
\hline
\end{tabular}




\begin{tabular}{|c|c|c|c|c|}
\hline 5 & $\begin{array}{l}\text { Selection } \\
\text { decision Results }\end{array}$ & Non-conforming & Non-conforming & \\
\hline 6 & $\begin{array}{l}\text { Basis of } \\
\text { determination }\end{array}$ & $\begin{array}{l}\text { Working torque and maximum } \\
\text { torque exceeding motor rated } \\
\text { torque and maximum torque }\end{array}$ & $\begin{array}{l}\text { The working torque exceeds the rated } \\
\text { torque of the motor and the load inertia } \\
\text { ratio exceeds the specified value }\end{array}$ & \\
\hline 7 & $\begin{array}{l}\text { Re-selection of } \\
\text { motor, reducer }\end{array}$ & $\begin{array}{l}\text { HG-SR702BG1 type } \\
\text { KB180-29-S2-P2 }\end{array}$ & $\begin{array}{l}\text { HG-SR502J( unchanged ) } \\
\text { KB180-17-S2-P2 }\end{array}$ & $\begin{array}{l}\text { Mitsubishi } \\
\text { Brand }\end{array}$ \\
\hline 8 & $\begin{array}{l}\text { Related Motor } \\
\text { parameters }\end{array}$ & $\begin{array}{l}\text { (1) rated Speed } 2000 \mathrm{r} / \mathrm{min} \\
\text { (2) Maximum speed } 3000 \mathrm{r} / \mathrm{min} \\
\text { (3) inertial } 161 \mathrm{~kg} \cdot \mathrm{cm}^{2} \\
\text { (4) rated torque } 33.4 \mathrm{Nm} \text {, } \\
\text { maximum torque } \mathrm{Nm}\end{array}$ & $\begin{array}{l}\text { (1) rated Speed } 2000 \mathrm{r} / \mathrm{min} \\
\text { (2) Maximum speed } 3000 \mathrm{r} / \mathrm{min} \\
\text { (3) inertia } 99.7 \mathrm{~kg} \cdot \mathrm{cm}^{2} \\
\text { (4) rated torque } 23.9 \mathrm{Nm} \text {, } \\
\text { maximum torque } 71.6 \mathrm{Nm}\end{array}$ & \\
\hline 10 & $\begin{array}{l}\text { Load condition } \\
\text { converted to } \\
\text { the shaft end } \\
\text { of the motor }\end{array}$ & $\begin{array}{l}\text { (1) Speed } 926.3 \mathrm{r} / \mathrm{min} \\
\text { (2) Maximum Speed } 1140 \mathrm{r} / \mathrm{min} \\
\text { (3) Inertial } 24.5 \mathrm{~kg} \cdot \mathrm{cm}^{2} \\
\text { (4) working torque } 26.3 \mathrm{Nm} \text {, } \\
\text { maximum torque } 62.3 \mathrm{Nm}\end{array}$ & $\begin{array}{l}\text { (1) Rated Speed } 1912.5 \mathrm{r} / \mathrm{min} \\
\text { (2) Maximum Speed } 2762.5 \mathrm{r} / \mathrm{min} \\
\text { (3) Inertial } 133 \mathrm{~kg} \cdot \mathrm{cm}^{2} \\
\text { (4) working torque } 14.5 \mathrm{~nm} \text {, } \\
\text { maximum torque } 21.6 \mathrm{~nm}\end{array}$ & \\
\hline 11 & $\begin{array}{l}\text { Selection } \\
\text { decision Results }\end{array}$ & Qualified & Qualified & \\
\hline
\end{tabular}

Personal CV: Wang Chaoqun (1974---) Man AnhuiYingShang Bachelor of Engineers, Double Star Tire Co., Ltd. is engaged in rubber equipment technology work, published 23 papers. Contact: Qingdao Road, Huangdao District, Shandong Province, No. 666 Doublestar R\&amp; d Center1410004241@qq.com

\section{References}

[1] LiuCaixia TOM-L5641 CNC Milling Machine servo motor selection and calculation [J] Journal of Baotou Vocational and Technical College P25-26 Issue 3rd of 2014

[2] Xiao Xiao et al. Selection principle and calculation of servo motor [J] machine tool \& amp; Hydraulic 2014 issue 22 nd P46

[3]Wangjianghong et al. Calculation and selection of X-axis servo motor for CNC gantry milling machine [J] Machinery Manufacturing 2016 12th month P10-11

[4]Fanwei et al.Selection and calculation of AC servo motor feeding in machining center [J] Electromechanical technology 2017 8th month P48-49 